Acknowledgement. G.N. was supported by a research grant from Hoffmann-La Roche, Basel, to SLJ.

1. Liaaen-Jensen, S. In Isler, O., Ed., Carotenoids, Birkhäuser, Basel 1971, p. 77.

2. Petracek, F. J. and Zechmeister, L. J. Amer. Chem. Soc. 78 (1956) 1427.

3. Curl, L. J. Food Res. 21 (1956) 689.

4. Liaaen-Jensen, S. and Hertzberg, S. Acta Chem. Scand. 20 (1966) 1703.

5. Karrer, P. and Takahashi, T. Helv. Chim. Acta 16 (1933) 1163.

6. Kuhn, R., Trischmann, H. and Löw, I. Angew. Chem. 67 (1955) 32.

7. Kuhn, R., Baer, H. H. and Seeliger, A. Justus Liebigs Ann. Chem. 611 (1958) 236.

8. Wallenfels, K., Bechtler, G., Kuhn, R., Trischmann, H. and Egge, H. Angew. Chem. 75 (1963) 1014.

9. Müller, H. and Karrer, P. Helv. Chim. Acta 48 (1965) 291.

10. Nybraaten, G. and Liaaen-Jensen, S. Acta Chem. Scand. B 28 (1974) 485.

11. Liaaen-Jensen, S. Kgl. Nor. Vidensk. Selsk. Skr. (1962) No. 8.

12. Kuhn, R., Lederer, E. and Deutsch, A. Hoppe-Seyler's Z. Physiol. Chem. 220 (1933) 229.

13. Nybraaten, G. and Liaaen-Jensen, S. Acta Chem. Scand. 25 (1971) 370.

14. Vetter, W., Englert, G., Rigassi, N. and Schwieter, U. In Isler, O., Ed., Carotenoids, Birkhäuser, Basel 1971, Chapter VI.

15. Arpin, N., Kjøsen, H., Francis, G. W. and Liaaen-Jensen, S. Phytochemistry 12 (1973) 2751.

16. Stoochnoff, B. A. and Benoiton, N. L. Tetrahedron Lett. 71 (1973) 21.

17. McCormick, A. and Liaaen-Jensen, S. Acta Chem. Scand. 20 (1966) 1989.

18. Kuhn, R. and Lederer, E. Ber. Deut. Chem. Ges. B 65 (1932) 639.

19. Unpublished data.

20. Nybraaten, G. Thesis, Norwegian Inst. Technology, Univ. Trondheim, Trondheim 1973.

Received March 28, 1974.

\section{The Reaction between Phosphonium Ylides and Isocyanates, a Convenient Route to Ketenimines PAUL FRØYEN}

\author{
Chemical Institute, University of Bergen, \\ N-5014 Bergen, Norway
}

Reactions of phosphonium ylides with isocyanates have been reported in a few papers. In 1919 Staudinger and Meyer ${ }^{1}$ found that triphenyl ketenimine (II) could be prepared from phenyl isocyanate by reaction with diphenylmethylene triphenylphosphorane $\left(I ; R^{1}=R^{2}=\right.$ $\mathrm{Ph}$ )

$$
\mathrm{Ph}_{3} \mathrm{P}=\mathrm{CR}^{1} \mathrm{R}^{2}+\mathrm{Ph}-\mathrm{N}=\mathrm{C}=\mathrm{O} \rightarrow
$$

(I)

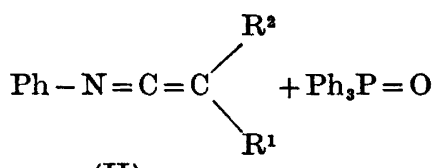

(II)

Although this was the first preparation of a ketenimine, no yield was reported and no attempt was made to extend the synthesis to other ketenimines. Later, however, Trippett and Walker ${ }^{2}$ studied the reactions of phenyl isocyanate with a series of ylides, but no ketenimine was formed during these reactions. It was reported that the reaction between the "non-stabilized" ylide dimethylmethylene triphenylphosphorane $\left(I ; \mathbf{R}^{1}=\mathbf{R}^{2}=\mathrm{CH}_{3}\right)$ and phen$y 1$ isocyanate stops at the betaine stage. In other cases, when the ylide under investigation contained an $\alpha$-hydrogen atom, migration of that hydrogen occurred, a new ylide being formed:

$$
\begin{aligned}
& \mathrm{Ph}_{3} \mathrm{P}=\mathrm{CHR}+\mathrm{Ph}-\mathrm{N}=\mathrm{C}=\mathrm{O} \rightarrow \\
& \mathrm{Ph}_{3} \stackrel{+}{\mathrm{P}}-\mathrm{CHR} \\
& \overline{\mathrm{O}}-\mathrm{C}=\mathrm{NPh} \rightarrow \mathrm{Ph}_{3} \mathrm{P}=\mathrm{CR}-\mathrm{C}(\mathrm{O}) \mathrm{NHPh}
\end{aligned}
$$

Finally, Ratts and Partos ${ }^{3}$ attempted the following reaction:

$$
\begin{aligned}
& \mathrm{Ph}_{3} \mathrm{P}=\mathrm{C}=\mathrm{C}=\mathrm{CPh}_{2}+\mathrm{CH}_{3} \mathrm{~N}=\mathrm{C}=\mathrm{O} \rightarrow \\
& \mathrm{Ph}_{2} \mathrm{C}=\mathrm{C}=\mathrm{C}=\mathrm{C}=\mathrm{NCH}_{3}
\end{aligned}
$$

(III)

and were able to isolate the amide of the cumulene imine (III). As far as the present author knows, there have been no other attempt to make ketenimines along this route. Thus, no ordinary ketenimine, except the one synthesized by Staudinger and Meyer has been prepared by 


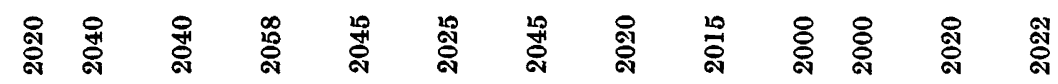

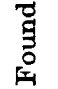

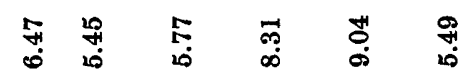

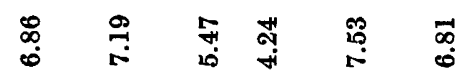

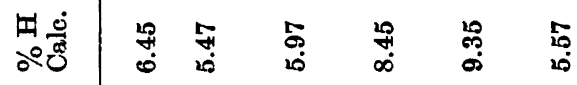

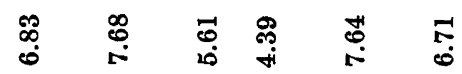

萦

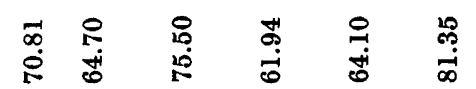

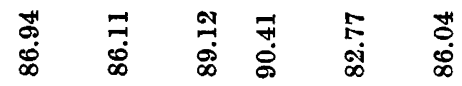

○ீंల్

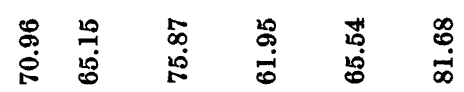

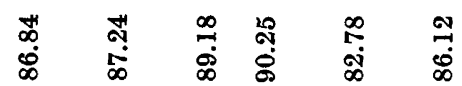

꿀

乖유

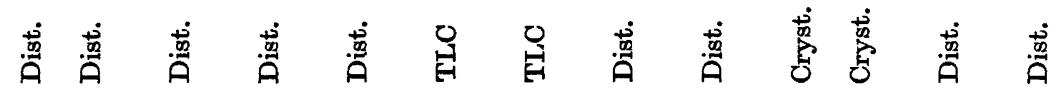

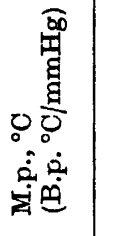

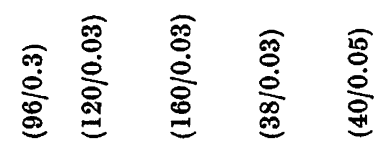

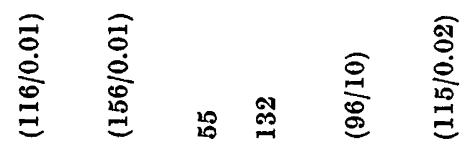

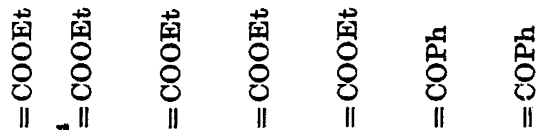

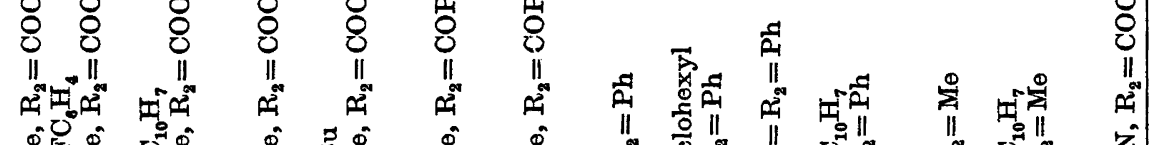
A

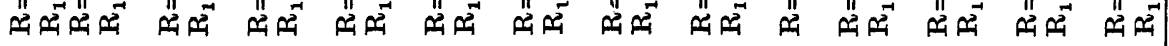

\section{Acta Chem. Scand. B 28 (1974) No. 5}


the ylide-isocyanate reaction. The lack of interest in the Staudinger-Meyer synthesis of ketenimines is remarkable, particularly in view of the cumbersome methods currently used for the preparation of these compounds. No single reaction for the preparation of ketenimines has the character of a general reaction. The method most widely used is perhaps the dehydration of $N$-monosubstituted amides, but this preparation gives good yields only in the case of triarylsubstituted compounds.

In order to test the synthetic potential of the ylide-isocyanate method, the present author has undertaken a study of the formation of ketenimines from the reaction of isocyanates with a series of phosphonium ylides $\mathrm{Ph}_{3} \mathbf{P}=$ $\mathrm{CR}^{1} \mathbf{R}^{2}$, representing both non-stabilized ylides, i.e. $\mathrm{pK}$ of the carbon acid $\mathrm{CH}_{2} \mathrm{R}^{1} \mathrm{R}^{2}>37$, and stabilized ylides i.e. $\mathrm{p} K$ of $\mathrm{CH}_{2} \mathrm{R}^{1} \mathrm{R}^{2}<35$. The ylide used in the reactions $8,9,10$, and 11 (Table 1 ) is of borderline stability ( $p K$ of $\mathrm{CH}_{2} \mathrm{Ph}_{2} \simeq 35$ on the McEwen scale.) The expected ketenimine was isolated in all cases except one. A summary of the results is given in Table 1. The reaction appears in most cases to proceed quantitatively as judged by the amount of triphenylphosphine oxide isolated and by the characteristic infrared absorption at approximately $2000 \mathrm{~cm}^{-1}$. In several cases, however, some material is lost by polymerization during the work-up.

As can be seen from Table 1 , the reaction works equally well with aliphatic and aromatic isocyanates, although the latter react under milder conditions. Non-stabilized ylides do undergo the reaction, but not as readily as moderately stabilized ylides. Thus in the case of 12 and 13 (Table 1) comparatively stable intermediates were formed and the reactions could not be completed at $80^{\circ} \mathrm{C}$ (boiling ben. zene). When the ylide was present in a pure state the second step of the reaction could be performed at $130-150^{\circ} \mathrm{C}$ in mesitylene. However, non-stabilized ylides are most conveniently prepared in situ from the corresponding phosphonium salt and alkyl or aryl lithium. When this procedure is applied, lithium halides will be present in the reaction mixture and seriously affect the reactivity of the ylides. In the case of 13 an attempt was made to perform the reaction along this route. The first step of the reaction went smoothly, but the subsequent decomposition of the intermediate to triphenylphosphine oxide and $N$ - $\alpha$-naphthyl dimethylketenimine could not be performed under the abovementioned conditions. Heating for one hour at $170^{\circ} \mathrm{C}$ (boiling mesitylene) gave only a trace of the expected products. This result was not unexpected, however, since it is well known from studies of the Wittig reaction that Lewis acids, particularly lithium salts, co-ordinate with the ylides and with the forming intermediates, and the olefin forming step may only be performed under forcing conditions.
In the case of (14), $\mathrm{R}^{1}=\mathrm{CN}, \mathrm{R}^{2}=\mathrm{COOC}_{2} \mathrm{H}_{5}$ ) no reaction was observed in boiling benzene. This negative result may be attributed to the extraordinary strong electron-withdrawing groups linked to the carbanion portion of the ylide. The interaction between the ylide carbon and the cyano and ester groups is reflected in a considerable decrease in the nucleophilicity of the ylide, and thereby in its reactivity towards isocyanates. Disubstituted phosphonium ylides were applied in all cases because monosubstituted ylides $\left(\mathrm{Ph}_{3} \mathrm{P}=\mathrm{CHR}\right)$ undergo a prototropic shift at the intermediate stage of the reaction forming a new ylide. ${ }^{2}$

Experimental. Materials. The phosphonium ylides were prepared by the "salt method" on treatment of a solution of the appropriate phosphonium salt with a suitable base. The stabilized ylides were generated with sodium ethoxide in anhydrous ethanol and recrystallized from benzene. Dimethyl- and diphenylmethylene triphenylphosphorane were prepared in liquid ammonia, using sodium amide as a base.

Synthesis of ketenimines (Table 1). In a dry $150 \mathrm{ml}$, two necked, roundbottomed flask $\theta$ quipped with a magnetic stirrer, a nitrogen inlet, and a reflux condenser with drying tube was placed $50 \mathrm{ml}$ of dry benzene, and $0.01 \mathrm{~mol}$ of ylide. Thereafter $0.01 \mathrm{~mol}$ of isocyanate was slowly added. The reaction mixture was vigorously stirred during the addition. In the case of $4,5,9,10$, and 11 (Table 1 ) the reaction mixture was refluxed for several hours in a slow current of dry nitrogen. 8 was heated at $100^{\circ} \mathrm{C}$ in an autoclave for $24 \mathrm{~h}$. In the case of 12 and 13 the reactions were completed after about $5 \mathrm{~min}$ at $140^{\circ} \mathrm{C}$ in mesitylene. In the other cases, however, the reaction went to completion in a few minutes at ambient tem. perature. The ketenimine formation was always recognized on the strong infrared absorption at approximately $2000 \mathrm{~cm}^{-1}$. The product was worked up without further heating if no sign of the infrared isocyanate band at $2150 \mathrm{~cm}^{-1}$ was observed. The benzene was evaporated in vacuo whereafter the ketenimine was extracted with petroleum ether. After evaporation of this solvent, the ketenimines were purified by distillation or by recrystallization. In two cases $(6$ and 7, Table 1) the product was unstable and could not be purified by distillation.

1. Staudinger, H. and Meyer, J. Helv. Chim. Acta 2 (1919) 619.

2. Trippett, S. and Walker, D. M. J. Chem. Soc. (1959) 3874.

3. Ratts, K. W. and Partos, R. D. J. Amer. Chem. Soc. 91 (1969) 6112.

4. Stevens, C. I. and Singhal, G. H. J. Org. Chem. 29 (1964) 34.

Received April 4, 1974. 